TECHNICAL TRANSACTIONS 12/2019

CIVIL ENGINEERING

DOI: $10.4467 / 2353737$ XCT.19.128.11453 SUBMISSION OF THE FINAL VERSION: 9/12/2019

\author{
Kamil Słowiński (D) orcid.org/0000-0002-4225-520X \\ kamil.slowinski@polsl.pl \\ Department of Building Structures, Faculty of Civil Engineering, Silesian University of \\ Technology in Gliwice
}

Marek Piekarczyk iD orcid.org/0000-0003-0566-4749

Chair of Bridge, Metal and Timber, Faculty of Civil Engineering, Cracow University of Technology.

\title{
FEM DETERMINATION OF THE PLASTIC LIMIT LOAD FOR CYLINDRICAL SHELLS
}

\author{
WYZNACZANIE NOŚNOŚCI PLASTYCZNEJ POWŁOK CYLINDRYCZNYCH \\ NA PODSTAWIE ANALIZY NUMERYCZNEJ MES
}

\begin{abstract}
In this paper a new approach to the consistent identification of the deformation pattern vital for the precise determination of the plastic limit load of a cylindrical shell from MNA when using modified Southwell (MS) and Tangent Stiffness (TS) plots is presented. It is proposed that the formalised assessment of the plastic collapse load can be done by the application of the relation between the load factor increment $\Delta r_{R}$ and the arc length $s$ - for an identification of achievement of the complete plastic collapse mechanism from MNA, and then the MS or TS plot for the displacement pattern that corresponds to the identified plastic mechanism.
\end{abstract}

Keywords: cylindrical shell, plastic collapse, nonlinear analysis

\section{Streszczenie}

W artykule przedstawiono metodę pozwalającą na jednoznaczną identyfikację postaci deformacji kluczowej w procesie wyznaczania nośności plastycznej powłoki cylindrycznej z analizy MNA, przy zastosowaniu zmodyfikowanej zależności Southwella (MS) oraz metody sztywności stycznej (TS). Proponuje się, żeby formalna ocena plastycznego obciążenia niszczącego oparta była na wykorzystaniu zależności między przyrostem mnożnika obciążenia $\Delta r_{R}$ i długością łuku $s$ - w celu identyfikacji momentu osiągnięcia w analizie kompletnego mechanizmu zniszczenia, a następnie zastosowaniu wykresów zależności MS i TS dla postaci deformacji stowarzyszonej z wskazanym wcześniej mechanizmem.

Słowa kluczowe: powłoka cylindryczna, zniszczenie plastyczne, analiza nieliniowa 


\section{Introduction}

The global numerical MNA/LBA design methodology is widely recommended to be used for the buckling strength assessment of steel shells $[1,2]$. Usually, this design format permits to achieve less conservative results in comparison with the stress design approach, acc. to [3] and, at the same time, is much more simple to use in practical applications than the global numerical geometrically and materially nonlinear analysis with imperfections (GMNIA) [4].

The MNA/LBA design procedure uses the materially nonlinear analysis (MNA) and the linear bifurcation analysis (LBA) to access the overall relative slenderness for a shell. A precise assessment of the overall shell slenderness, which is essentially important in problems of elastic-plastic buckling, requires a rigorous evaluation of the elastic critical buckling load and the plastic limit load for a shell. While extraction of the elastic critical buckling load from an eigenvalue analysis is a relatively simple matter, derivation of the plastic limit load from materially nonlinear analysis is much more onerous demand.

According to provisions of the European standard for design of steel shells [3], the plastic resistance of a shell should be obtained through the MNA analysis of a perfect shell, using small displacement theory. As a result of the numerical calculations, relationship between the load factor $r_{R}$ which is a multiplier on design loads, and the peak deformation $w$ at the point on the shell surface can be obtained. Then, the asymptotic value for plotted $r_{R}-w$ relation may be taken as the plastic reference resistance ratio $r_{\text {Rpl }}$ (which is the largest multiplier achieved from the analysis).

This approach can be easily applied only for cylindrical shells under axisymmetric loading conditions, e.g. for shells subjected to uniform pressure, where the plastic mechanism is governed by membrane yielding [5]. Usually, in such cases, it is also possible to calibrate numerical model by comparing numerical results with analytical solutions. Wide range of such closed-form solutions is presented in [6].

However, for shells under complex loading conditions, it is usually difficult to obtain a suitably long yield plateau on the $r_{R}-w$ relation to clearly indicate the true plastic strength. For shells where plasticity is dominated by localized bending the load-displacement curve may become flat at very large deformations corresponding to the load that is far in excess of the real plastic strength of a shell. On the other hand, the numerical calculations may be prematurely terminated which produces load-displacement curve that is still rising at the end of the analysis. In such cases development of the plastic mechanism in numerical model requires a large number of increments of nonlinear analysis.

For such cases the plastic strength can be identified using alternative techniques. One of them, recommended in [1], is a modified Southwell plot. Originally this graphical method was dedicated for evaluation of the elastic critical loads of frame systems [7]. Applications of this method for cylindrical shells under simple and complex loading conditions are presented, among others, in [5, 8] and [9]. This plot presents data as the load factor $r_{\mathrm{R}}$ against ratio $r_{R} / w$, where $w$ is deformation that seemed to be critical. The modified Southwell plot permits to indicate a precise value of the plastic reference resistance ratio $r_{\mathrm{Rpl}}$ even when a complete plastic mechanism has not been achieved during the numerical computations [5]. This estimation is 
based on assumption that the plasticity in a given area of the shell is associated with the small change in applied load $\left(r_{R}\right)$ and the high rate of reduction of the secant stiffness $\left(r_{R} / w\right)$.

However, when provisions from the modified Southwell plot are based on data obtained well before an achievement of the complete plastic mechanism in numerical analysis it is desirable to access the accuracy of these provisions using a Convergence Indicator Plot (CIP), proposed in [5]. The CIP presents data as the provisions of the plastic limit load from modified Southwell plot against the parameter $\omega$ which is an indicator of the proximity of the load $r_{R, i}$ in a given increment $i$ to the plastic reference resistance ratio $r_{R, M S, i}$ extracted from the MS plot (i.e. $\left.\left(r_{R, M S, i}-r_{R, i}\right) / r_{R, i}\right)$. The intercept of $r_{R, M S, i}-\omega$ curve (or regression lines for all data points) on the ordinate axis can be taken as the plastic collapse load of a shell.

The third graphical technique that enables estimation of the plastic limit load from MNA is Tangent Stiffness Plot (TS). The predictive power of this method for many different cases, i.e. shells, flat plates and plates with imperfections, cylindrical shells, cold-formed U-sections or hot-rolled I-sections, was presented in [10]. The main advantage of TS plot is that it does not require such calculation effort as modified Southwell plot or the convergence indicator factor plot. It uses the measure of reduction in tangent stiffness in a given area of a structural element which corresponds to the development of plastic mechanism in numerical model. It presents data as the tangent stiffness reduction factor $\tau_{\kappa}$ against load factor $r_{R}$, where $\tau_{\kappa}$ is a quotient of the tangent stiffness $K_{i}$ (i.e. the actual slope of the load-deformation curve) at a given increment $i$ and the initial stiffness $K_{\text {ini }}$. The load value at which $\tau_{\kappa}$ achieves value of 0.01 (i.e. $K_{i}$ drops to $1 \%$ of $K_{i n i}$ ) is taken as the plastic limit load. For further details the reader is referred to [10].

The common denominator for the presented graphical techniques is the dependence of their provisions on the chosen deformation pattern. The chosen displacement pattern, i.e. its location and its direction must correspond to the plastic collapse mechanism for the whole shell. The consequences of different choices of the displacement patterns when using MS plots are illustrated in [5] for the cylindrical shell supported on local brackets. It was shown that selection of displacement which was seemed to be the most intuitive gave $81 \%$ overestimation of the correct value of the plastic collapse load. In such cases, determination of the accurate values may require to trial the MS- or CIP and TS plots for different points on the shell surface which may require significant calculation effort.

Sometimes, the final form of the plastic collapse mechanism is unknown at the beginning of the analysis. The shell may start yielding relatively early, which can be an argument for the analyst to terminate the computations. However, achievement of the complete plastic collapse mechanism may require development of local plastic strains in several locations on the shell surface which may involve a large number of additional increments in numerical computations. In such a case, the analysis is terminated prematurely and the displacement pattern selected- and deemed to be critical at given stage of the analysis is not of the crucial importance for the development of the complete plastic collapse mechanism for the whole shell. In such a case, provisions of MS-, CIP- or TS plots will also be incorrect.

This article shows the problem of a consistent identification of the deformation pattern that should be taken for the determination of the plastic limit load of cylindrical shells 
from MNA when using MS- and TS plots. Thorough the paper a new graphical technique, using relationship between the load factor increment and arc length, is developed for such identification. The problems encountered when using MS- and TS plots and the potential of the proposed supplementary technique are discussed for a finite element models of a steel cylindrical shell subjected to simple- and complex loading conditions.

\section{Finite element model}

The numerical models of the shell under consideration were modelled in form of the halfpart cylinder using the finite element analysis software Abaqus [11]. The cylinder geometry with radius to thickness ratio $r / t=7.28 .8$ with thickness $t=5 \mathrm{~mm}$ and height $H \approx 2.4 r$ was adopted for all calculations (Fig. 1). Elastic-perfectly plastic material model was taken for the analysis with the yield surface described by Huber - Mises - Hencky yield function with: the Young's modulus $E=210 \mathrm{GPa}$, Poisson's ratio $v=0.3$ and yield stress $f_{y}=235 \mathrm{MPa}$. The general-purpose, 4-node quadrilateral shell elements $\mathrm{S} 4 \mathrm{R}$ with reduced integration and the hourglass control were applied. Seven integration points were utilized through the wall thickness. The mesh size was adopted individually for each of the considered load case. The cylinder was simply supported at the bottom edge and restrained against out-of-round deformations at the top edge, which reflects the boundary conditions $\mathrm{BC} 2$ and $\mathrm{BC} 1$, according to [2].

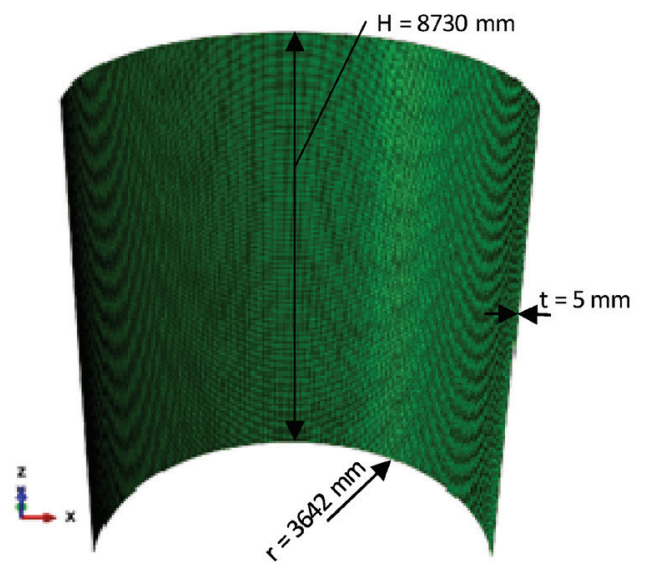

Fig. 1. Geometry of the finite element model

The materially nonlinear analysis (MNA) was performed using the modified Riks method $[11]$ in a regime of small displacement theory, neglecting geometrical nonlinearities. This computational algorithm is mainly utilised to geometrically nonlinear static problems with unstable response of an element. However, it can also be used for problems with nonlinear material characteristics $[5,12]$. All calculations were performed with the specified parameters of a Riks step along the static equilibrium path, as follows: the initial and maximum arc length increment of the same value, the total arc length scale factor equal to 1.0, and the minimum 
arc length increment computed automatically by the automatic incrementation algorithm. This last set permits to reduce the arc length when a severe nonlinearity appears during the analysis.

\section{Shell under simple loading conditions}

Identification of the deformation pattern that is vital for the development of plastic mechanism for shells subjected to horizontal ring loading or uniform internal pressure (Fig. 2) is a relatively simple matter. However, these well documented examples with easily identified form of the plastic mechanism are utilised here to develop a new graphical method that will simplify the procedure of identification of the critical deformation pattern for shells with more complex pattern of the plastic collapse mechanism.
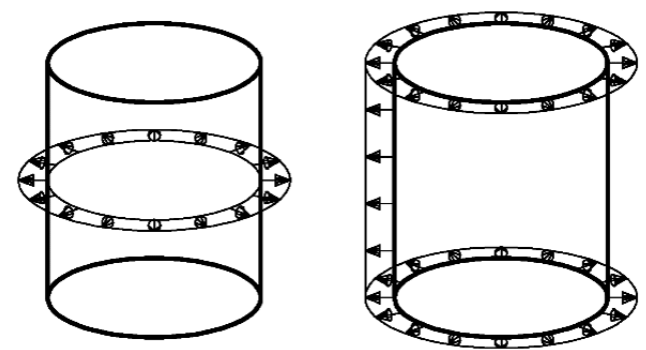

Fig. 2. Investigated shells subjected to (from left): ring loading, uniform internal pressure

\subsection{Extraction of plastic limit load from MS plot and TS plot}

The adequacy of the modified Southwell plot and tangent stiffness plot for extraction of the plastic strength for a ring-loaded shell and a shell subjected to uniform pressure (Fig. 1) was proved in [5] and [10]. Both problems have analytical solutions, documented in [6]. The plastic limit reference ratio for shell subjected to ring loading (1) and uniform internal pressure (2) may be calculated form expressions:

$$
\begin{gathered}
r_{R, l}=1.949 \frac{f_{y} \cdot t}{F_{r e f}} \sqrt{\frac{t}{r}} \\
r_{R, l}=\frac{f_{y} \cdot t}{r \cdot p_{r e f}}\left(1+\frac{1}{1+2 \varpi^{2}}\right)
\end{gathered}
$$

For the ring-loaded shell the uniform line load $F_{r e f}=1 \mathrm{kN} / \mathrm{m}$ was applied in the plane of symmetry of the shell. In the step definition 2000 arc length increments were specified with an initial, minimum and maximum arc length increments of $0.5,1.0 \cdot 10^{-10}$ and 0.5 , respectively. For the shell subjected to uniform internal pressure of magnitude $p_{\text {ref }}=1 \mathrm{kN} / \mathrm{m}^{2}$, the step parameters were specified, as follows: 1000 arc length increments with an initial, minimum and maximum arc length increments of $1.0,1.0 \cdot 10^{-5}$ and 1.0 , respectively. 
The numerically obtained paths of equilibrium for the considered shells are presented in Fig. 3. As it can be seen from relation between the load factor $r_{R}$ and peak displacement $w$, the analytically determined values of the plastic reference resistance ratio $r_{R, l}$ of 84.8 (from Eq. 1) and 322.7 (from Eq. 2) are very close to the maximum values of the load factor $r_{R, \max }$ obtained from numerical analysis. However in case of the shell under uniform pressure the numerical computations were automatically terminated before achievement of declared maximum number of arc length increments since the required increment was less than the minimum specified.

a)
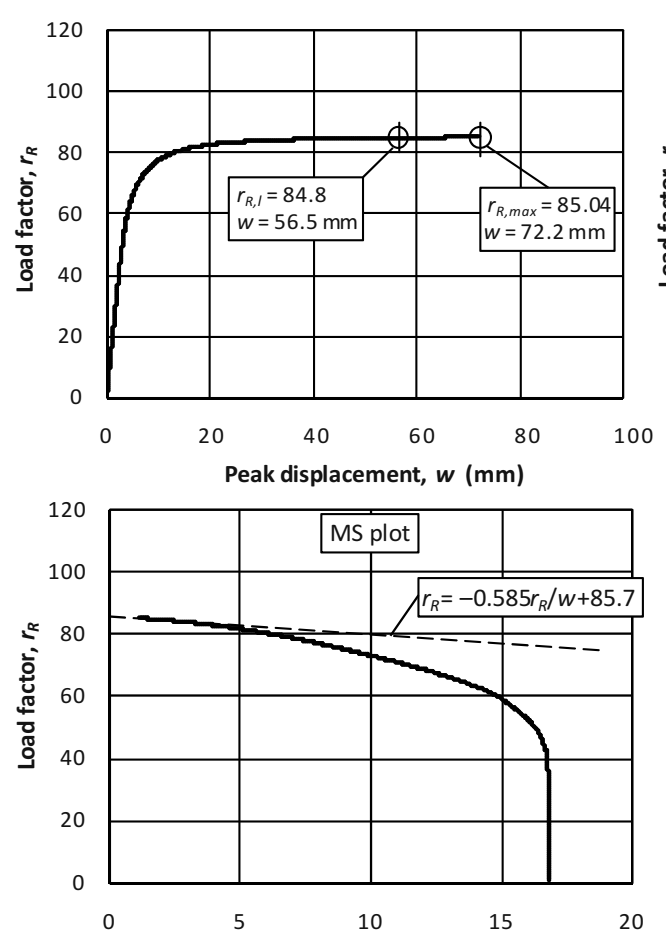

Load factor/peak displacement, $r_{R} / w(1 / \mathrm{mm})$

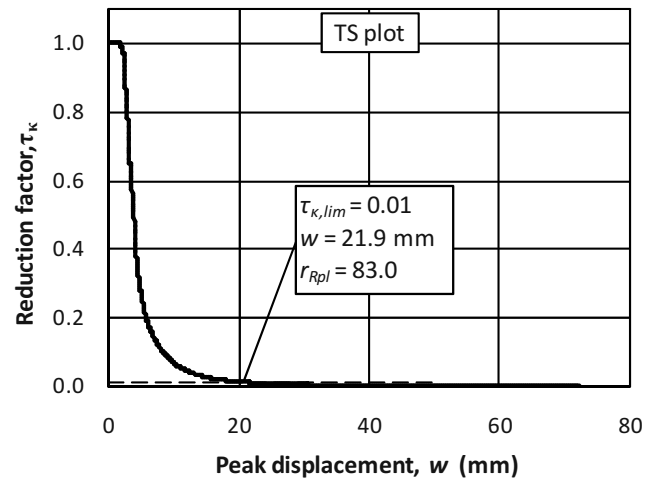

b)
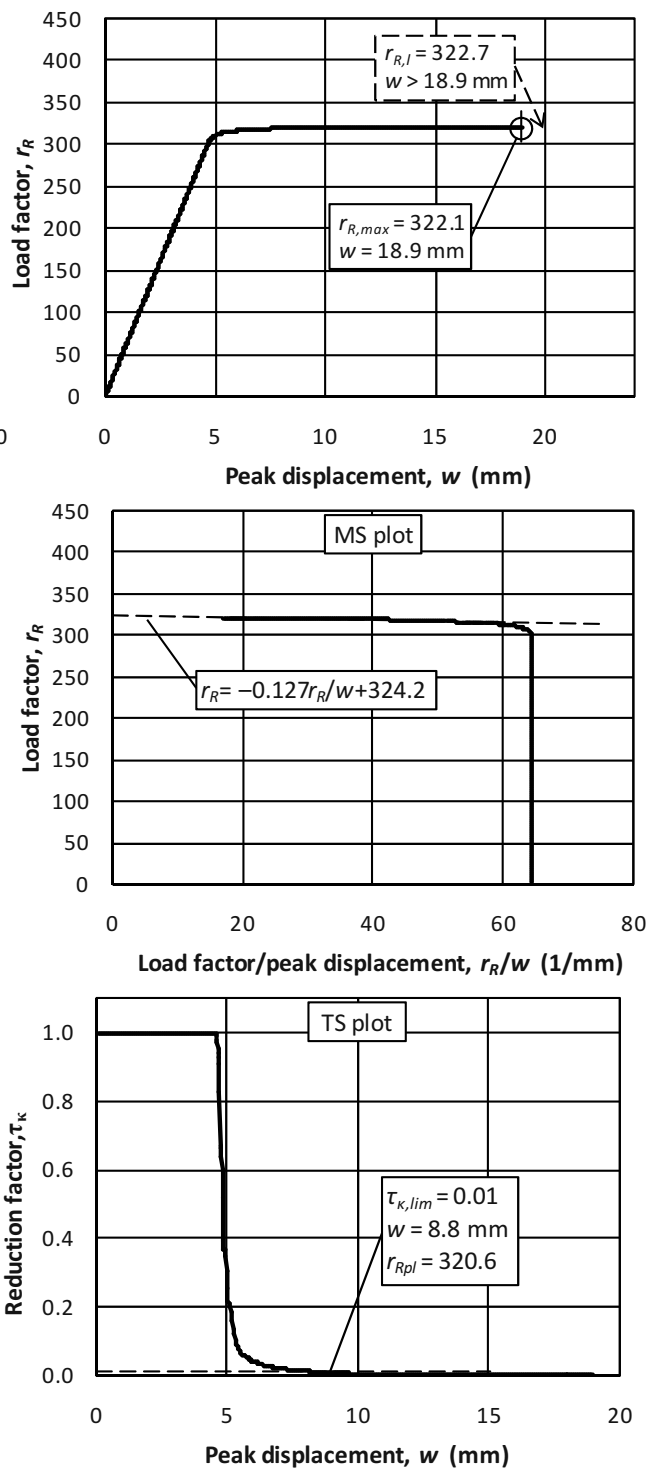

Fig. 3. Paths of equilibrium for a shell subjected to: a) ring loading, b) uniform internal pressure 
The curves constructed from the modified Southwell plots (MS plots in Fig. 3) for both considered load cases, initially are vertical, which indicates the elastic range of behaviour of the shells. The first kink of the curves corresponds to the first yield on the shell surface. Departure from the kink to the linear, almost horizontal portion of the curves, corresponds to the development of plastic field in shells. This second portion of the curves is of crucial importance, since the intercepts of regression lines (dashed lines), drawn using three last data points acc. to [5], with the ordinate axes are taken as projections of the plastic limit reference ratio $r_{\mathrm{Rpl}}$. It should be noted however, that usually a series of regression lines is necessary to make since the plastic limit load should be taken as the lowest projection on the vertical axis. The extracted values of $r_{R p l}$ are 85.7 and 324.4,which gives $1 \%$ and $0.5 \%$ overestimation of theoretical results.

The tangent stiffness reduction plot (TS plot, in Fig. 3) produces curves that initially are horizontal, i.e. where tangent stiffness reduction factor $\tau_{k}=1.0$, which represents the elastic stage of behaviour of the considered shells. The departure from horizontal to almost vertical path corresponds to the beginning of the elastic-plastic range and further development of plasticity in elements. This second portion illustrates a decrement of the tangent stiffness in a point located in the plastic field, relative to the initial elastic stiffness. Extraction of load factor $r_{R}$ corresponding to $\tau_{x, \text { lim }}=0.01$ gives $r_{R, p l}$ ratios of 83 and 320.6 , which gives $2 \%$ and $0.5 \%$ underestimation of analytically determined values for shell subjected to ring loading and uniform pressure, respectively.

Comparison of numerical results with closed-form analytical solutions shows the predictive power of MS- and TS plots. The obtained results will be used to show the process of development of a new graphical method that supplies the procedure of identification of the deformation pattern for the precise extraction of the plastic limit load from MS- and TS plots.

\subsection{Development of a new graphical technique}

It is difficult to indicate a universal rule for the choice of the displacement pattern for Ms- and TS plots. However, the general consideration is that the chosen displacement pattern must be associated with the development of a plastic collapse mechanism of a shell. For the considered shells subjected to ring loading or uniform internal pressure this choice is relatively easy since, as it might be supposed, the critical displacement pattern is a peak displacement which is normal to the shell surface. The progressive plasticity is indicated from MS- or TS plots in form of the rate of reduction of the secant stiffness or the tangent stiffness, respectively, at one-selected point on the shell surface. However, the initiation and the further development of the plastic mechanism in both shells can be also indicated by consideration the course of relation between the load factor increment $\Delta r_{R}$ and the arc length $s$. The load factor increment is one of the unknowns in Riks method, while the arc length is used to measure the progress of the solution [11]. These both parameters correspond to the structural response of the whole element under consideration. The $\Delta r_{R}-s$ relations for the ring-loaded shell and the under uniform pressure are presented in Fig. 4. Initially, the curves are horizontal (i.e. $\Delta r_{R}$ has its initial value) which corresponds to the stage where both shells remain elastic. The first yield on the shell surfaces is followed by a sudden drop in values of the load factor increment $\Delta r_{R}$. As the shells experience significant plasticity the curves 
become almost vertical. The end of the vertical potions is followed by a smoothed bent and transition to the linear almost horizontal portion of the curves, where $\Delta r_{R}$ tends to be zero. This graphical technique takes advantage from the feature of the modified Riks algorithm where the development of the plastic strain in a material, at a given arc length, is associated with the reduction of load increments. As it can be seen from Fig. 4, for both considered load cases, the difference in values of the plastic reference resistance ratio extracted from MS- and TS plots (which gave slight over- and underestimation of the analytical values, respectively), is realized within the linear portion of the $\Delta r_{R}-s$ relations, where $\Delta r_{R}$ is close to zero. It can be also seen, that coordinates from provisions of the TS plots are located in the vicinity of the transition from the smoothed bent to the linear-almost horizontal portion of the curves. At these transition points, the load factor increments $\Delta r_{R, T S}$ achieve 1.2 and $2.9 \%$ of their initially set values for the ring-loaded shell and the shell under uniform pressure, respectively. Such decrement in value of load factor increment permits to assume, for further considerations, that the beginning of the bottom linear portion of the $\Delta r_{R}-s$ relation indicates the initiation of the plastic collapse mechanism for the shells under consideration.
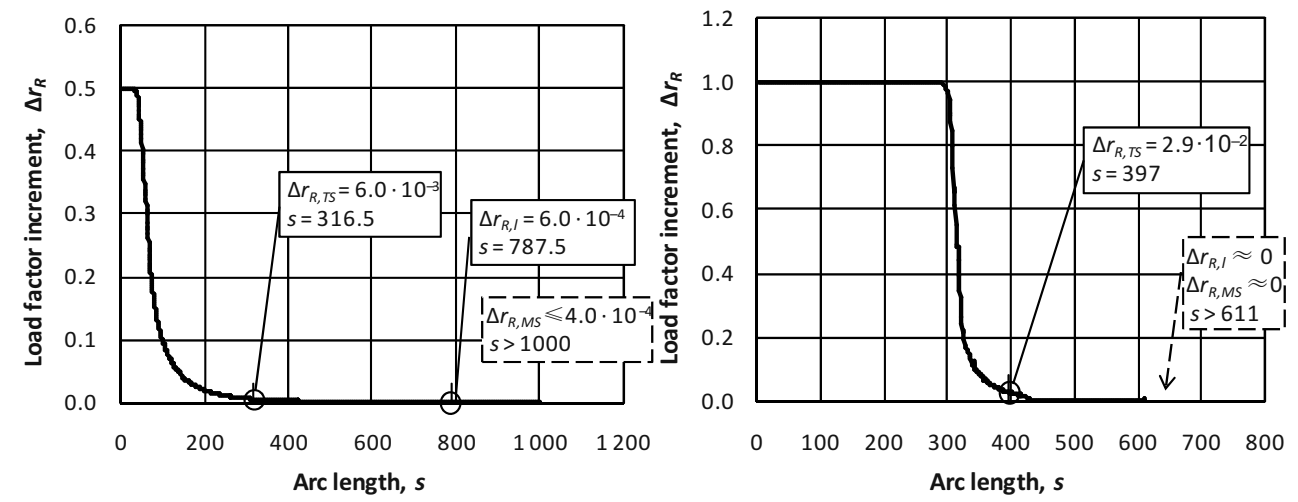

Fig. 4. Relations between load factor increment and arc length for shell subjected to (from left): ring loading, uniform internal pressure

It should be recapitulated that the presented graphical method is based on parameters of the MNA that corresponds to the structural response of the whole shell rather than the limited-arbitrarily selected portion of the shell. This potential feature of this method will be examined for identification of the critical deformation pattern in shell subjected to complex loading conditions, where the pattern of the plastic collapse mechanism is unknown at the beginning of the analysis.

\section{Shell under complex loading conditions}

To reflect complex loading conditions the shell was loaded by design combination of dead load and wind action (on X axis direction, Fig. 1). For the Riks analysis 2000 arc length increments were specified with their initial, minimum and maximum values of 1.0, 
$1.0 \cdot 10^{-10}$ and 1.0, respectively. Computations were automatically terminated at the 1824 arc length increment when the necessary increment size was less than the minimum specified. The shell in a final deformed configuration is presented in Fig. 5. Points 1 and 2, marked in Fig. 5, indicate areas of the shell surface with the several plastic strains that were developed at different stages of the numerical computations. In point 1, peak deformations within the plastic field were associated with attainment of the full thickness yield, first - in vicinity of the bottom edge, and then - near the top edge of the shell, within the first 100 increments. Point 2 indicates the area of the severe plastic straining that developed within the range of further 100 increments ( 200 increments in total). It should be noted here that attainment of the peak deformation in point 2 was associated with achievement of the final deformed configuration of the shell; in progress of computations only scale of deformations was changing. The paths of static equilibrium for points 1 and 2 and $\Delta r_{R}-s$ relations plotted at 100 increment and the last - 1824 increment are presented in Fig. 6.

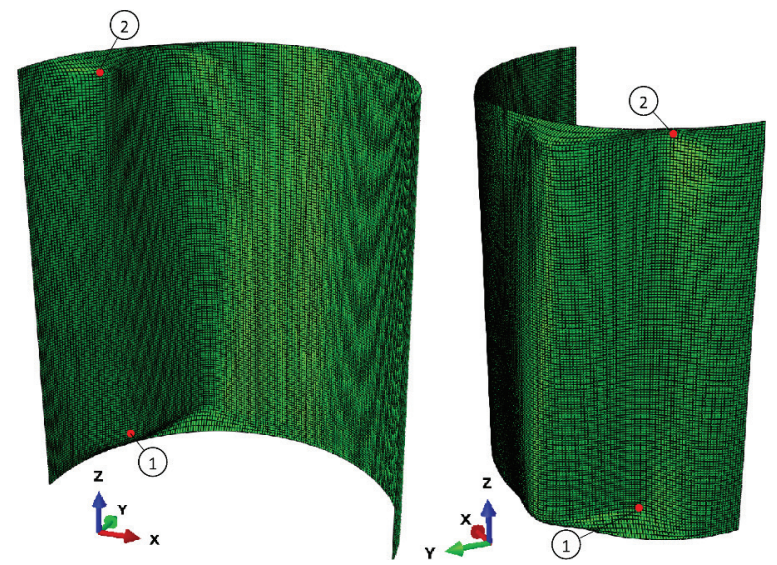

Fig. 5. The finite element model in a final deformed configuration (deformation scale factor is equal to 1.0)

As it can be seen in Fig. 6, the modified Southwell plots $\left(r_{R}-r_{R} / w\right)$ and tangent stiffness plots $\left(\tau_{\kappa}-r_{R}\right)$ predict two different values of the plastic limit load for the two selected displacement patterns (in point 1 and 2) which were supposed to be critical at different stages of the analysis. In the considered case the choice of the proper displacement pattern is difficult since the pattern of the plastic collapse mechanism is unknown at the beginning of the analysis. To identify the phenomena involved in development of the plastic collapse visualisation module of Abaqus was used [11]. These phenomena are indicated on $\Delta r_{R}-s$ relations by letters A, B, $\mathrm{C}$ and $\mathrm{D}$. Coordinates of the letters $\mathrm{A}, \mathrm{B}$ and $\mathrm{C}$ correspond to: the first yield on the shell surface, full thickness yield in a limited area near the bottom and the top edge of the shell, respectively. These phenomena were identified within the first 100 increments of the analysis. The lower slope of the $\Delta r_{R}-s$ curve between points B and C provides information that the spread of plasticity is gradual and plasticity is dominated by bending. It can be also seen that at this stage of analysis the load factor increment achieved $17 \%$ of its initial value, which can be assessed as a significant reserve. It can be therefore assumed that the selected displacement pattern in point 1 is not associated with the complete plastic mechanism of the shell. 

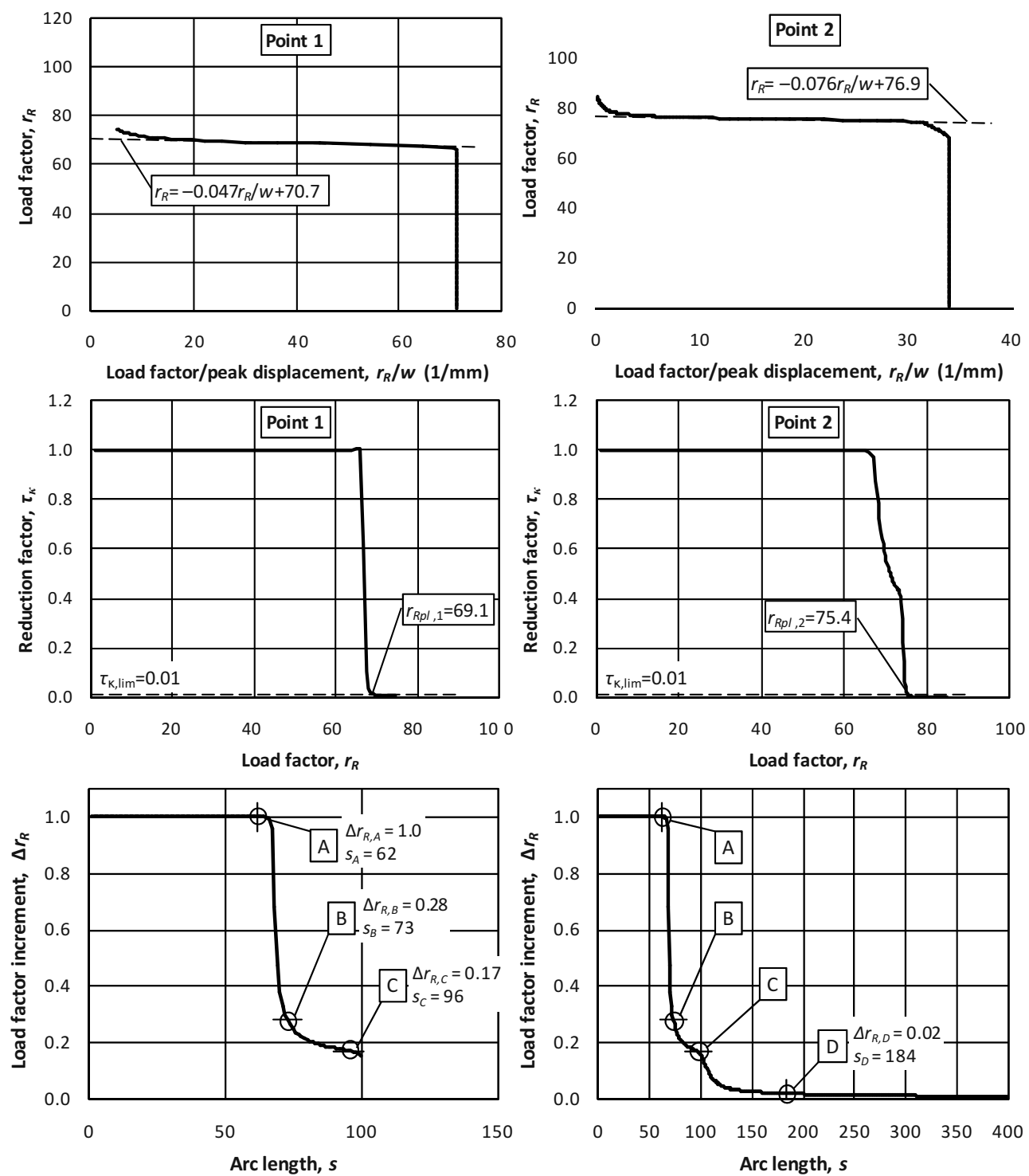

Fig. 6. Paths of equilibrium obtained at: a) 100 increment, b) 1824 increment

(for clarity only inital part of $\Delta r_{R}-s$ relation was plotted)

Within the further 100 increments of the analysis, the factor $\Delta r_{R}$ was reduced to $2 \%$ of the initial value which illustrates that the element experiences significant spread of plasticity. Coordinates for point marked with the letter $\mathrm{D}$ indicate beginning of the severe plastic straining at point 2 on the shell surface, which was associated with the achievement of the final pattern of deformation of the shell. For higher loads, excessive yielding of the shell, accompanied by unrealistically large deformations, was observed. It suffices to state that coordinates for point $\mathrm{D}$ in $\Delta r_{R}-s$ curve indicate the development of the complete plastic collapse mechanism of the shell. Therefore the displacement pattern in point 2 (Fig. 5) can be 
used for a precise predictions of the plastic limit load from the MS- and TS plots. Note that, similarly as for shells under simple loading conditions, point $\mathrm{D}$ is located in vicinity of the transition from the nonlinear bent to the linear portion of the $\Delta r_{R}$-s relation, where $\Delta r_{R}$ tends to be zero. It proves that the proposed graphical method can be used for identification of the plastic collapse mechanism and the corresponded deformation pattern for a determination of the plastic limit load from MS- and TS plots.

\section{Conclusions}

The extraction of the plastic collapse load from the modified Southwell plot (MS) or the tangent stiffness plot (TS) is a challenging task if the collapse mechanism involves high local strains occurring at different locations on the shell surface, at different stages of the analysis. In such cases it may be necessary to trial the MS- and TS plots for different locations which can make these graphical methods impractical.

In this paper a new approach to the consistent identification of the critical deformation pattern for the precise determination of the plastic limit load from MNA when using MS- and TS plots was developed and examined. It is proposed that the formalised assessment of the plastic collapse load can be done by the usage of the relation between the load factor increment $\Delta r_{R}$ and the arc length $s$, and then the modified Southwell plot or the tangent stiffness plot. In this approach the MS- or TS plots should be applied to the displacement pattern that was identified, from $\Delta r_{R}-s$ relation, to be associated with the plastic collapse mechanism of a shell.

The $\Delta r_{R}-s$ relation permits to track the structural response of the whole element during the progress of the numerical analysis. The curves obtained for examined shells under simple and complex loading conditions reveals a sudden decrement in value of the load factor increment after first yield and further spread of plasticity. The obtained results clearly indicate that the bottom, linear portion of the $\Delta r_{R}$-s curve (i.e. where $\Delta r_{R}$ tends to be zero) shows the equilibrium associated with the plastic collapse mechanism. The transition from the smoothed bent to the beginning of the linear portion the $\Delta r_{R}-s$ curve can be treated as the achievement of the complete plastic mechanism. Application of the MS- or TS plots to the displacement pattern with a peak plastic strain that corresponds to the plastic collapse permits for a precise extraction of the plastic limit load for a cylindrical shell.

It is worth to mention that the proposed graphical method is a practical alternative for time-consuming visual assessment of the stress/strain state in shell, done during the progress of the analysis to identify the pattern of the plastic collapse mechanism that is unknown at the beginning of the analysis.

The above findings suggest that the transition from the nonlinear to the linear portion of the $\Delta r_{R}-s$ curve can be treated as a condition for the termination of numerical calculations which allows for reduction of the computational expense. 


\section{References}

[1] European Convention for Contructional Steelwork, Buckling of steel shells. European design recommendations $5^{\text {th }}$ edition, ECCS, 2008.

[2] Rotter J.M., Shell buckling design and assessment and the LBA-MNA methodology, "Stahlbau", Vol. 80(11)/2011, 791-803.

[3] EN 1993-1-6 Eurocode 3. Design of steel structures. Part 1-6: Strength and stability of shell structures, CEN, Brussels 2007.

[4] Michałowski T., Piekarczyk M.T., Selected issues of special steel structures. Chimneys, silos, tanks, Wydawnictwo PK, Kraków 2019.

[5] Doerich C., Rotter J.M., Accurate determination of plastic collpase loads from finite element analysis, "Journal of Pressure Vessel Technology", Vol. 133(1)/2011.

[6] Save M.A., Massonnet C.E., Plastic analysis and design of plates, shells and disks, North-Holland Publishing Company, Amsterdam-London 1972.

[7] Horne M.R., Merchant W., The stability of frames, Pergamon Press, Oxford 1965.

[8] Holst J.M.F.G., Rotter J.M., Gillie M., Münch M., Failure criteria for shells on local brackets, New Approaches to Structural Mechanics, Shells and Biological Structures, Kluwer Academic Publishers, London 2002.

[9] Gillie M., Holst J.M.F.G, Structural behaviour of silos supported on discrete, eccentric brackets, "Journal of Constructional Steel Research", Vol. 59/2003, 887-910.

[10] Santos G.B., Gardner L., Kucukler M., A method for the numerical derivation of plastic collapse loads, “Thin-Walled Structures”, Vol. 124/2018, 258-277.

[11] Hibbit, Karlsson and Sorenson Inc., Abaqus/Standard user's manual - Version 6.1, 2000.

[12] Fiołek P., Jakubowski J., Local buckling of highly corroded hot-rolled box-sections beams, "Journal of Constructional Steel Research", Vol. 157/2019, 303-311. 